\title{
Comparison of homologous and heterologous prime-boost immunizations combining MVA-vectored and plant-derived VP2 as a strategy against IBDV
}

\author{
Matías Richetta $^{\mathrm{a}, \mathrm{b}}$, Evangelina Gómez ${ }^{\mathrm{a}, \mathrm{b}}$, María Soledad Lucero ${ }^{\mathrm{a}}$, Silvina Chimeno Zoth ${ }^{\mathrm{a}, \mathrm{b}}$, \\ María José Gravisaco a, Gabriela Calamante ${ }^{\mathrm{a}}$, Analía Berinstein ${ }^{\mathrm{a}, \mathrm{b}, *}$ \\ a Instituto de Biotecnología, CICVyA, INTA, Castelar, CC 25 B1712WAA, Buenos Aires, Argentina \\ ${ }^{\mathrm{b}}$ Consejo Nacional de Investigaciones Científicas y Tecnológicas (CONICET), Rivadavia 1917, C1033AAV Ciudad de Buenos Aires, Argentina
}

\section{A R T I C L E I N F O}

\section{Article history:}

Received 28 July 2016

Received in revised form 17 October 2016

Accepted 7 November 2016

Available online 18 November 2016

\section{Keywords:}

Avian immune response

Subunit vaccine

Recombinant MVA

IBDV

\begin{abstract}
A B S T R A C T
Different immunogens such as subunit, DNA or live viral-vectored vaccines against Infectious Bursal Disease virus (IBDV) have been evaluated in the last years. However, the heterologous prime-boost approach using recombinant modified vaccinia Ankara virus (rMVA), which has shown promising results in both mammals and chickens, has not been tried against this pathogen yet. IBD is a highly contagious and immunosuppressive disease of poultry that affects mainly young chicks. It is caused by IBDV, a double-stranded RNA virus carrying its main antigenic epitopes on the capsid protein VP2. Our objective was to evaluate the immune response elicited by two heterologous prime-boost schemes combining an rMVA carrying the VP2 mature gene (rVP2) and a recombinant VP2 protein produced in Nicotiana benthamiana (pVP2), and to compare them with the performance of the homologous pVP2-pVP2 scheme usually used in our laboratory. The SPF chickens immunized with the three evaluated schemes elicited significantly higher anti-VP2 antibody titers $(p<0.001)$ and seroneutralizing titers $(p<0.05)$ and had less T-cell infiltration ( $p<0.001)$, histological damage $(\mathrm{p}<0.001)$ and IBDV particles $(\mathrm{p}<0.001)$ in their bursae of Fabricius when compared with control groups. No significant differences were found between both heterologous schemes and the homologous one. However, the rVP2-pVP2 scheme showed significantly higher anti-VP2 antibody titers than pVP2-rVP2 and a similar tendency was found in the seroneutralization assay. Conversely, pVP2-rVP2 had the best performance when evaluated through bursal parameters despite having a less potent humoral immune response. These findings suggest that the order in which rVP2 and pVP2 are combined can influence the immune response obtained. Besides, the lack of a strong humoral immune response did not lessen the ability to protect from IBDV challenge. Therefore, further research is needed to evaluate the mechanisms by which these immunogens are working in order to define the combination that performs better against IBDV.
\end{abstract}

(c) 2016 Elsevier Ltd. All rights reserved.

\section{Introduction}

Infectious Bursal Disease (IBD) is a highly contagious and immunosuppressive disease of poultry that affects mainly young chicks [1]. It is caused by the Infectious Bursal Disease Virus

\footnotetext{
* Corresponding author at: Instituto de Biotecnología, CICVyA, INTA, Castelar, CC 25 B1712WAA, Buenos Aires, Argentina.

E-mail addresses: richetta.matias@inta.gob.ar (M. Richetta),gomez.evangelina@ inta.gob.ar (E. Gómez), lucero.soledad@inta.gob.ar (M.S. Lucero), chimenozoth. silvina@inta.gob.ar (S. Chimeno Zoth), gravisaco.maria@inta.gob.ar (M.J. Gravisaco), calamante.gabriela@inta.gob.ar (G. Calamante), berinstein.analia@inta.gob.ar (A. Berinstein).
}

(IBDV), a bi-segmented double-stranded RNA virus [2] carrying its main antigenic epitopes on the capsid protein VP2 [3]. This viral pathogen targets IgM bearing B-lymphocytes in the bursa of Fabricius (BF) [4]. The economic losses caused by IBDV are due to increased susceptibility to other pathogens and poor vaccine efficacy because of the immunosuppression acquired by the animals, but can also be caused by high mortality in flocks infected with very virulent IBDV strains [5].

IBD is essentially controlled through vaccination. Vaccines against IBDV should be given relatively early because of the chicken's susceptibility period to the disease. At present, the most widely used immunogens are based on live attenuated IBDV 
strains, even though they may cause immunosuppression and bursal atrophy, and are effective only when IBDV maternal antibodies have decreased [6].

In order to overcome these issues, different immunogens such as subunit, DNA or live viral-vectored vaccines have been rationally designed and evaluated [6,7]. Our group has had successful experiences immunizing chickens with VP2 protein produced both in Nicotiana benthamiana plants [8] and through non replicative poxviral vectors [9-11].

To induce broader immune responses, different heterologous prime-boost regimes have been successfully used in mammals [12]. Particularly, recombinant modified vaccinia Ankara virus (rMVA) has shown to be more effective when used as a heterologous boost after priming with the same antigen in a different form [13], both in mammal $[14,15]$ and avian [16] models. On the other hand, a poxvirus prime-protein boost scheme has been considered the most successful vaccination protocol against HIV-1 [17].

Thus, having a consistently immunogenic protein as VP2 from $N$. benthamiana (pVP2), our objective was to investigate whether its combination with a recombinant MVA expressing VP2 (rVP2) in a heterologous prime-boost scheme could elicit a stronger immune response than the one induced by the homologous scheme based on pVP2. This is, to the best of our knowledge, the first trial combining a recombinant MVA with a recombinant protein as a strategy against IBDV in chickens.

\section{Materials and methods}

\subsection{Animals}

Specific pathogen free (SPF) embryonated eggs were purchased from Instituto Rosenbusch S.A. (Argentina) and hatched in an automatic incubator (Yonar, Argentina). Chickens were housed in individual cages with food and water provision ad libitum. All procedures involving the use of animals were performed in agreement with institutional guidelines and approved by the Institutional Committee for the Care and Use of Experimental Animals (CICUAE - CICVyA - INTA).

\subsection{Immunogens}

Recombinant MVA viruses have been previously obtained in our laboratory: rVP2 [9] and MVA-GFP (rGFP) carry the coding sequence of IBDV-VP2 mature protein or the gene coding for the green fluorescent protein (GFP), respectively.

MVA viruses were amplified in primary Chicken Embryo Fibroblasts (CEFs) cultured in Dulbecco's Modified Eagle Medium (DMEM) (Thermo Fisher Scientific, USA) supplemented with $2 \%$ fetal bovine serum (Internegocios, Argentina) at $37^{\circ} \mathrm{C}$ with $5 \%$ of $\mathrm{CO}_{2}$. When $90-100 \%$ cytopathic effect (CPE) was detected, cells and supernatant were collected together and 3 freeze-thaw cycles were performed to release the virus.

The other antigen, pVP2, which also had its GFP-control (pGFP), was extracted from pEAQ vector-infiltrated leaves [18] in a blender with 3 volumes of chilled buffer containing phosphate buffered saline (PBS) pH 7.3, complete EDTA-free protease inhibition cocktail tablets (Roche, Germany) and 0.04\% antifoam 0-30 (Sigma Aldrich, USA), and the expression of VP2 was evaluated through Western Blot as described in [8].

\subsection{Experimental design}

Thirty chicks were randomly divided in 5 groups and immunized intramuscularly (IM) as stated in Table 1. Chickens were bled
Table 1

Experimental design.

\begin{tabular}{llll}
\hline Group & 1st inoculation & 2nd inoculation & Challenge \\
\hline 1 & pVP2 $(8 \mu \mathrm{g})$ & pVP2 $(8 \mu \mathrm{g})$ & \\
2 & rVP2 $\left(6.5 \times 10^{5}\right.$ & pVP2 $(8 \mu \mathrm{g})$ & \\
& PFU $)$ & rVP2 $\left(6.5 \times 10^{5}\right.$ & $\begin{array}{l}8.25 \times 10^{6} \mathrm{PFU} / \\
\text { chicken }\end{array}$ \\
& pVP2 $(8 \mu \mathrm{g})$ & PFU $)$ & \\
4 & rGFP $\left(6.5 \times 10^{5}\right.$ & rGFP $\left(6.5 \times 10^{5}\right.$ & \\
& PFU $)$ & PFU $)$ & pGFP $(8 \mu \mathrm{g})$
\end{tabular}

Six specific pathogen free chickens were used in each group. Inoculations were performed at 14 days post hatch (1st) and 28 days post hatch (2nd). Animals were challenged three weeks after the 2nd inoculation and euthanized 5 days post challenge.

periodically by the wing vein, and the sera obtained were stored at $-20^{\circ} \mathrm{C}$ until use.

Three weeks after the boost immunization animals were challenged orally with $8.25 \times 10^{6}$ PFU of Winterfield strain of IBDV and euthanized five days post challenge.

\subsection{Anti-IBDV and anti-VP2 antibodies detection}

Sera obtained before challenge were analyzed using the IDEXX IBD test kit (IDEXX Laboratories, USA) following manufacturer's instructions.

In addition, sera were tested for specific anti-VP2 antibodies using an indirect ELISA based on subviral particles (SVP) formed by IBDV VP2. Briefly, 96-well Maxisorp ${ }^{\mathrm{TM}} \mathrm{Nunc}^{\mathrm{TM}}$ flat-bottom plates (Thermo Scientific, USA) were coated with $25 \mathrm{ng}$ of SVPs per well in $0.1 \mathrm{M}$ carbonate-bicarbonate buffer, $\mathrm{pH} 9.6$, overnight at $4{ }^{\circ} \mathrm{C}$. After blocking with $4 \%$ skim milk in PBS-T (0.05\% Tween 20$)$, plates were subsequently incubated with 3-fold serial dilutions of sample sera, and 1/3000 dilutions of goat anti-chicken IgG antibodies coupled to horseradish peroxidase (Bethyl Laboratories, USA). Revealing step was performed using ABTS substrate (Sigma-Aldrich, USA) $-\mathrm{H}_{2} \mathrm{O}_{2}$ in citric acid buffer, pH 5. Reading was done at $405 \mathrm{~nm}$ after 20 min of incubation. Antibody titers were calculated as the inverse of the highest dilution with an $\mathrm{OD}_{405 \mathrm{~nm}}$ value above the mean $+3.5 \mathrm{SD}$ of the negative control groups.

\subsection{Seroneutralization assay}

Sera were inactivated at $56{ }^{\circ} \mathrm{C}$ for $30 \mathrm{~min}$ and twofold serially diluted from $1 / 4$ to $1 / 8192$ in D-MEM. Dilutions were incubated with $100 \mathrm{TCID}_{50}$ of Winterfield strain of IBDV for $1 \mathrm{~h}$ at $37^{\circ} \mathrm{C}$ in 96-well plates (Greiner bio-one, Germany). After that, $100 \mu \mathrm{l}$ of a cell suspension of $1.5 \times 10^{6} \mathrm{CEFs} / \mathrm{ml}$ were added to each well. The cell suspension was prepared in D-MEM supplemented with $4 \%$ fetal bovine serum (FBS), $25 \mathrm{mM}$ HEPES and a mixture of antibiotic/antimycotic (Gibco ${ }^{\circledR}$, USA). Cells were cultured at $37^{\circ} \mathrm{C}$ with $5 \% \mathrm{CO}_{2}$ for 4 days, when CPE was observed. Seroneutralizing antibody ( $\mathrm{SN}$ ) titers were calculated as the inverse of the highest dilution showing no CPE.

\subsection{Lymphocyte isolation and flow cytometry analysis}

Lymphocytes were isolated from the BF as previously described [19]. Monoclonal antibodies (mAbs) (CD3-SPRD, CD4-PE, CD8 $\alpha-$ FITC) from Southern Biotech (Birmingham, USA) were employed. Cell suspensions were analyzed with a BD FACSCalibur Flow Cytometer (BD Biosciences, USA) and CellQuest software. The lymphocyte gate was defined by the forward/side scatter characteristics of the cells and 30,000 events were analyzed. 
The mean values of the bursae from three PBS-inoculated unchallenged SPF chickens were used for normalization of the values of all experimental groups.

\subsection{Histopathological analysis of the bursae}

Bursal samples were placed in $10 \%$ neutral buffered formalin and paraffin embedded. Sections of BF were stained with haematoxylin and eosin following standard histological procedures and they were microscopically examined for the presence of bursal lesions under light microscopy. The scoring scale of histological damage is shown in Table 2.

\subsection{IBDV isolation in CEFs}

Viral isolation assays were performed using pieces of bursa that had been kept at $-70^{\circ} \mathrm{C}$. They were mechanically disrupted in PBS and 3 frost/thaw cycles were performed. Homogenates were tenfold serially diluted and used to infect monolayers of CEFs seeded in 96-well plates as described in the seroneutralization assay. After 4 days at $37{ }^{\circ} \mathrm{C}$, presence of $\mathrm{CPE}$ was determined. Viral titers were expressed as TCID50/gr, using the Reed and Muench method [20].

\subsection{Statistical analysis}

Statistical analysis was done with GraphPad Prism Software version 5.01. Means were compared using one-way ANOVA followed by multiple rank comparisons with Tukey's test. A probability (p) value of $\leqslant 0.05$ was considered statistically significant.

\section{Results}

\subsection{Measurement of anti-IBDV and anti-VP2 humoral immune response}

Results of the analysis of serum samples are listed in Table 2. Considering the manufacturer's cut-off point, the homologous pVP2 scheme induced the most consistent humoral immune response as all chickens immunized with this regime elicited antibody titers above the mentioned point. In regard to heterologous schemes, 5 over 6 chickens immunized with rVP2/pVP2 and 2 out of 6 animals receiving pVP2/rVP2 were positive for the test. All the chickens in both control groups were negative. The progression of antibody titers over time is shown in Supplementary Fig. 1.

When testing the sera for specific anti-VP2 antibodies (Fig. 1), all chickens immunized with either homologous or heterologous VP2 schemes had significantly higher antibody titers than both control groups $(p<0.001)$. Although none of the heterologous schemes were significantly different compared to the homologous pVP2 scheme, the group receiving rVP2/pVP2 had a significantly higher antibody titer than the one vaccinated with pVP2/rVP2 $(p<0.05)$. These results demonstrated that homologous or heterologous prime-boost immunization schemes were able to induce an IBDV specific humoral response. Besides, this immune response was influenced by the order in which rVP2 and pVP2 were inoculated in heterologous vaccination schemes.

\subsection{Assessment of antibody neutralizing ability}

To determine if the antibodies produced were capable of neutralizing the virus, a seroneutralization assay was performed. In this experiment, all groups immunized with schemes including VP2 were able to elicit significantly higher SN titers than both control groups (Fig. 2). While there were no significant differences between titers from homologous and heterologous VP2-schemes, the median SN titer of the group immunized twice with pVP2 was considerably higher than the ones from both heterologous schemes.

\subsection{Evaluation of $T$ cell infiltration in the BF after challenge}

Increased infiltration of $\mathrm{T}$ lymphocytes into the $\mathrm{BF}$ has been associated with IBDV infection and replication in such organ $[19,21]$. Hence, the level of T cell infiltration in the bursa after challenge with IBDV can be taken as a parameter of vaccine protective efficacy. In this context, we analyzed the percentage of $\mathrm{T} \mathrm{CD}^{+}$ $\mathrm{CD}^{+}$and $\mathrm{CD}^{+} \mathrm{CD}^{+}$cells (Fig. 3 ) in the bursa of chickens challenged with a high dose of Winterfield strain of IBDV.

Regardless of the VP2-scheme received, all groups inoculated with this antigen had significantly less infiltration of $\mathrm{T}$ cells -both $\mathrm{CD}^{+}$and $\mathrm{CD}^{+}-$in their bursae than both control groups $(p<0.001)$. However, no significant differences were found between neither homologous vs. heterologous nor between heterologous schemes, showing that all VP2-schemes were effective to decrease $\mathrm{T}$ cell infiltration in BF.

\subsection{Analysis of morphopathological changes in the bursae}

The analysis of microscopic lesions produced by IBDV replication in the BF is a valid tool for measuring the infection severity in chickens [22]. Microscopic alterations include lymphoid necrosis, formation of cystic cavities, infiltration of heterophils and fibrosis [23]. Thus, a histopathological analysis was made to search for evidence of IBDV replication in chickens' bursae.

Histopathological scoring results are presented in Table 2. In agreement with the other results, all VP2-immunized

Table 2

Anti-IBDV antibodies, bursal damage and viral load.

\begin{tabular}{|c|c|c|c|c|c|c|c|}
\hline \multirow[t]{2}{*}{ Groups } & \multirow[t]{2}{*}{ IBD $\mathrm{Ab}^{\mathrm{A}}$} & \multicolumn{5}{|c|}{ Histopathological BF lesions $^{B}$} & \multirow[t]{2}{*}{ IBDV viral load $\left(\mathrm{TCID}_{50} / \mathrm{gr}\right)^{\mathrm{C}}$} \\
\hline & & Score 1 & Score 2 & Score 3 & Score 4 & Mean score \pm SD & \\
\hline pVP2 & $6 / 6$ & 3 & 3 & 0 & 0 & $1.5 \pm 0.5^{\mathrm{a}}$ & $<1.26 * 10^{3} / /^{\mathbf{a}}$ \\
\hline rVP2/pVP2 & $5 / 6$ & 3 & 3 & 0 & 0 & $1.5 \pm 0.5^{\mathrm{a}}$ & $<1.26 * 10^{3} / /^{\mathbf{a}}$ \\
\hline $\mathrm{pVP} 2 / \mathrm{rVP} 2$ & $2 / 6$ & 6 & 0 & 0 & 0 & $1.0^{\mathrm{a}}$ & $<1.26 * 10^{3} / /^{\mathbf{a}}$ \\
\hline rGFP & $0 / 6$ & 0 & 0 & 2 & 4 & $3.67 \pm 0.5^{\mathrm{b}}$ & $4.08 \pm 1.1 * 10^{5} / /^{\mathbf{b}}$ \\
\hline pGFP & $0 / 6$ & 0 & 0 & 3 & 3 & $3.5 \pm 0.5^{\mathrm{b}}$ & $2.6 \pm 1.53 * 10^{5} / /^{\mathbf{c}}$ \\
\hline
\end{tabular}

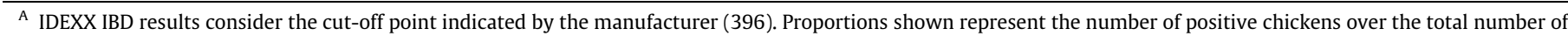
animals in each group $(n=6)$.

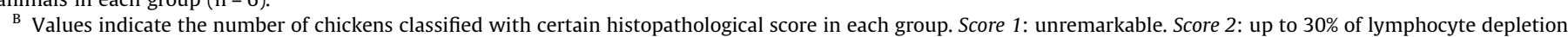

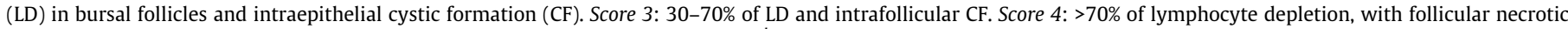
and/or fibrotic changes. The mean bursal score \pm SD of each group is also shown. ${ }^{a, b}$ Different letters along the scores indicate significant differences ( $p<0.001$ ).

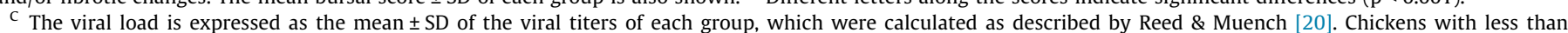

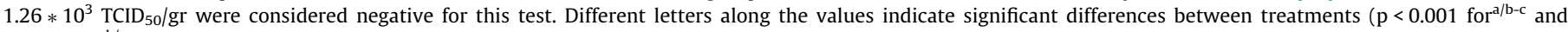
$\mathrm{p}<0.05$ for $\left.^{\mathrm{b} / \mathrm{c}}\right)$. 


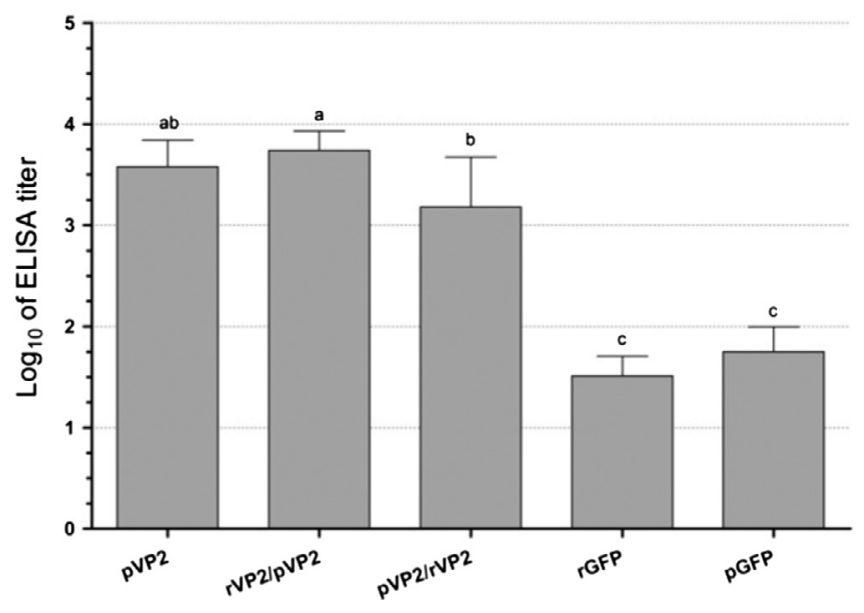

Fig. 1. Anti-VP2 antibody values evaluated through indirect ELISA. Sera from all chickens were tested just before challenge with IBDV. The antibody titers were Log10-transformed prior to analysis. Each column represents the mean value \pm SD of the corresponding group. ${ }^{\mathrm{a}, \mathrm{b}, \mathrm{c}}$ Different letters above bars indicate significant differences among treatments $(\mathrm{p}<0.05)$.

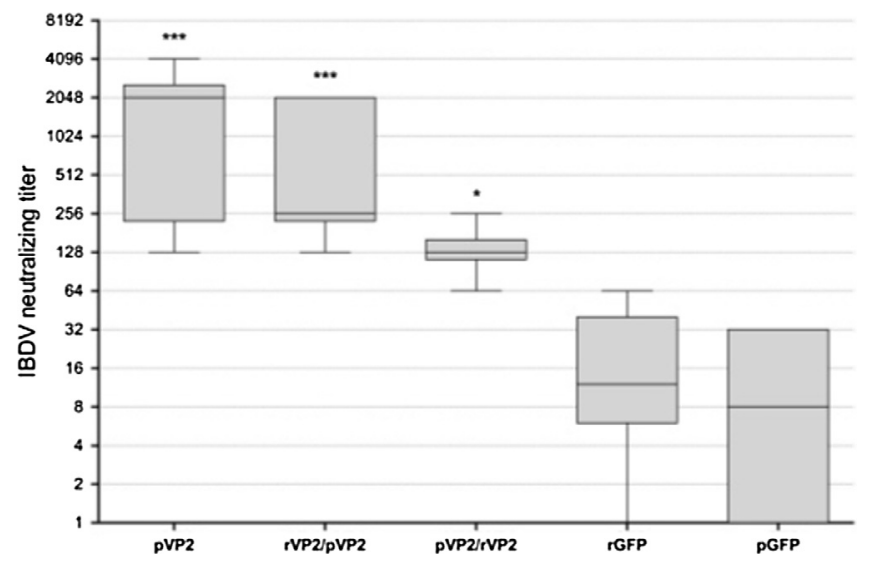

Fig. 2. Anti-IBDV neutralizing antibodies. A seroneutralization (SN) test was performed over the sera obtained just before challenge. The graph shows the median SN titer of each group (line inside the box) as well as the range of SN titers elicited. Asterisks above the boxes indicate significant differences between groups immunized with VP2 and both control groups $\left({ }^{* * *} \mathrm{p}<0.001\right.$ and $\left.{ }^{*} \mathrm{p}<0.05\right)$.

chickens had significantly lower scores than their counterpart GFP-immunized animals ( $\mathrm{p}<0.001$ ), indicating that VP2 antigen prevented histological damage. Although no significant differences were found between the schemes with IBDV antigen, animals that received pVP2 as a prime and $\mathrm{rVP} 2$ as a boost were completely and homogeneously protected, whereas groups immunized with the inverse heterologous or the homologous pVP2 schemes had up to $50 \%$ of their animals showing higher degree of pathological changes.

Images of the morphopathological changes in the bursae are included in Fig. 4.

\subsection{Quantification of IBDV viral load in $B F$}

The quantity of IBDV in BF after challenge can be used as an indicator of the protective efficacy of an experimental immunogen. In our experiment, results showed significantly higher IBDV titers in both control groups $(\mathrm{p}<0.001)$ compared to all groups immunized with either homologous or heterologous VP2 schemes
(Table 2). Although there were no differences among the three evaluated immunization schemes, approximately 200-fold and 300 -fold reductions of IBDV titer in BF were observed when comparing them with pGFP-group and rGFP-group, respectively.

\section{Discussion}

The use of heterologous prime-boost schemes has been widely explored in the last two decades. The key principles to support this rationale are the ability to elicit both humoral and cell-mediated immune responses and the avoidance of anti-vector immunity issues [12,24]. Recombinant poxviruses have been extensively tested in heterologous schemes and their effectiveness is the reason by which these vaccine vectors are currently among the most interesting candidates for HIV vaccines [25]. In mammals, recombinant MVA has been widely used as a booster in this kind of immunization protocols [26], showing better results when administered in that order [13]. Priming with DNA vaccines and boosting with non-replicative viral vectors has shown to be very effective to induce strong cell-mediated immunity [27]. On the other hand, either in mammals or chickens, proteic antigens are regarded as preferential stimulators of the humoral immune response and, thus, expected to elicit higher levels of antibodies than DNA or viral-vectored vaccines.

Successful experiences with heterologous prime-boost also exist in the avian model: DNA prime-inactivated vaccine boost [28-31], DNA prime-protein boost [32], recombinant Fowlpox prime-inactivated vaccine boost [33] and recombinant Adenovirus prime-recombinant MVA boost [16] have all shown to be more immunogenic when compared to homologous schemes.

In this context, we investigated: (a) whether a heterologous prime-boost immunization with a subunit VP2 vaccine and a recombinant MVA-VP2 could offer a higher anti-IBDV protective efficacy than the homologous prime-boost with the subunit VP2 and, (b) if the order in which immunogens were given could affect the immune response obtained.

As a general parameter of immunogenicity, anti-IBDV antibody titers were evaluated. In this assay, all the homologous pVP2 immunized animals were positive, whereas 5/6 animals immunized with rVP2/pVP2 scheme and $2 / 6$ receiving the inverse heterologous scheme were positive. A more specific anti-VP2 response was then evaluated, showing significantly better results in rVP2/pVP2 immunized animals compared to those chickens receiving the inverse sequence of antigens. Although none of the heterologous schemes were significantly different from the homologous one, here we had the first evidence that the order of administration of the different antigens might be important.

In agreement with previous reports, pVP2 elicited high SN titers [8]. In contrast, repeated immunizations with rVP2 had not resulted in a strong humoral response [9] and, thus, it was possible that the combination of both immunogens elicited less SN antibodies than the homologous pVP2 scheme. However, when comparing heterologous schemes there was a tendency towards a better performance of rVP2/pVP2 over the inverse one. Altogether, these findings suggest that the order in which both immunogens are combined can affect the humoral immune response obtained.

Gao and coworkers [32] have reported that a protein boost after a DNA priming resulted in the highest anti-IBDV humoral response, and other researchers have reported similar results using DNA prime-inactivated vaccine boost [28] or viral vectored primeinactivated vaccine boost [33]. Therefore, the rationale behind priming with a vectored antigen and boosting with a proteic one makes sense if what is sought is a strong humoral response while also stimulating cell-mediated immunity. As an additional advantage, it has been suggested that the smaller amount of antigen pro- 

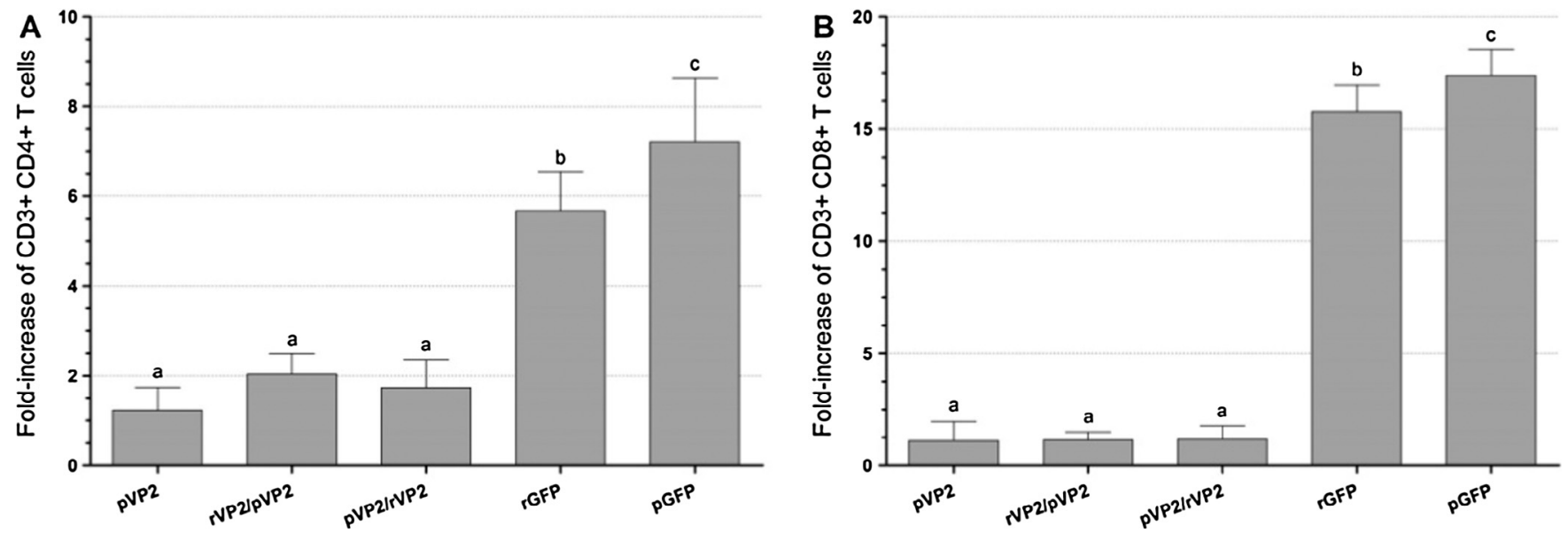

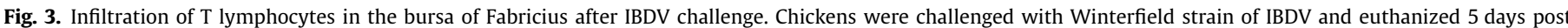

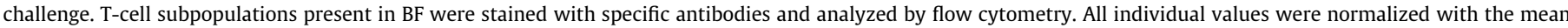

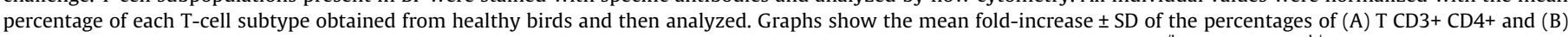
CD3+ CD8+ cells in each group. Different letters over the bars indicate significant differences among treatments $\left(p<0.001\right.$ for ${ }^{\mathrm{a} / \mathrm{b}-\mathrm{c}} ; \mathrm{p}<0.05$ for $\left.^{\mathrm{b} / \mathrm{c}}\right)$.
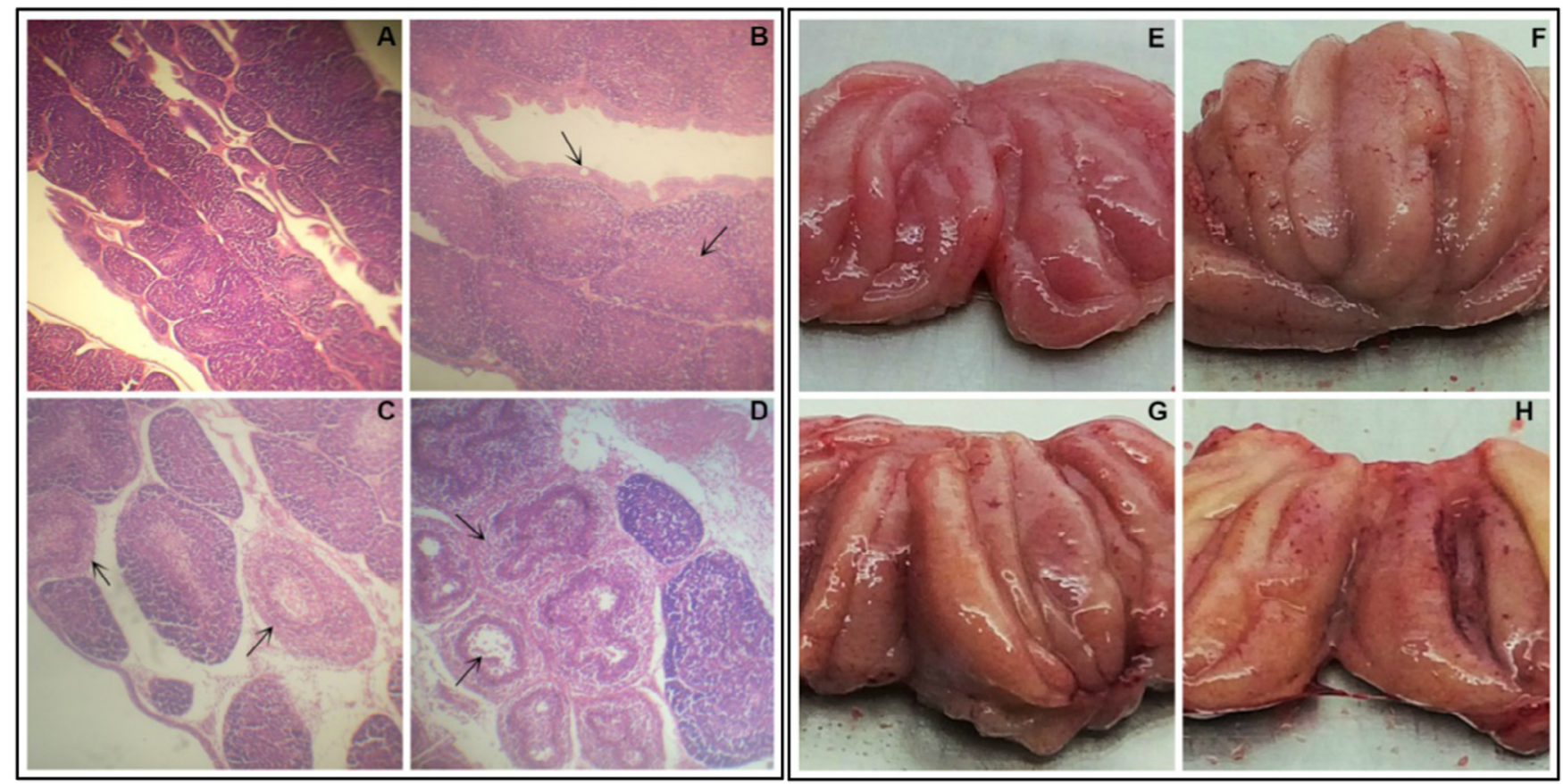

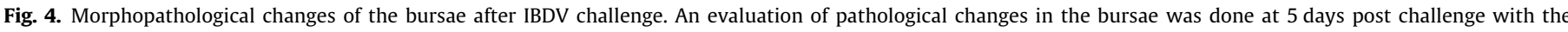

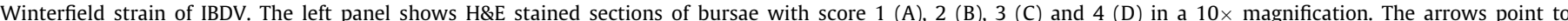

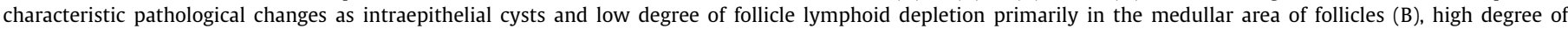

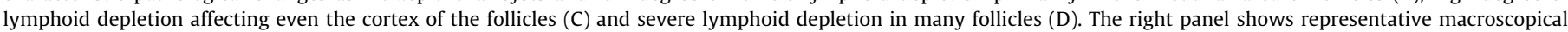

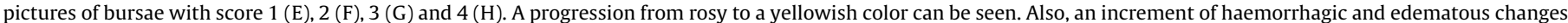
are observed within high-scoring bursae.

duced in the initial immunization in this kind of scheme could select for higher avidity in the antibodies produced [34].

Although neutralizing antibodies have been considered the most relevant tool to protect against IBDV infection, recent studies have raised doubt about the degree of dependence on them [35]. Some findings of our study support the hypothesis about the need of a more balanced immune response. When merging the results obtained in the analyses made on the bursae, we found that all the VP2-vaccinated animals had significantly less infiltration of T-cells $(\mathrm{p}<0.001)$, IBDV viral loads $(\mathrm{p}<0.001)$ and lower histopathological mean scores $(p<0.001)$ than the control groups. These results suggest that the three evaluated alternatives were able to prevent IBDV from reaching the BF or to enhance viral clearance from the affected tissue. However, an interesting finding of this study is that, despite not being significantly different, the histopathological scores were slightly better in the group primed with pVP2 and boosted with rVP2. This contrasts with the results of the humoral evaluation, although is consistent with other reports that found that less or even no detectable antibodies did not obliterate the ability of certain vaccine candidates to protect in both avian $[11,36,37]$ and mammalian $[38,39]$ models.

It should also be pointed out that T-cell-dependent viral clearance can induce bursal damage and delay follicle recovery [40], which may be the cause of mild histopathological damage in BF. 
Therefore, it can be thought that more viral particles reached the bursa in those animals receiving homologous pVP2 or heterologous rVP2/pVP2 schemes compared to chickens immunized with pVP2/ rVP2. However, further evaluations are needed to clarify the role of the antigen sequence over the slight differences in protection parameters.

Overall, the heterologous prime-boost approach did not show clear evidence of being better than the homologous one. However, the order in which the heterologous immunogens were delivered was able to influence over the immune response, as the rVP2/ pVP2 scheme performed better when evaluated through humoral immunity parameters, while pVP2/rVP2 was slightly better preventing bursal damage. In a real field situation, an ideal prime against IBDV should be able to surpass maternal antibodies at an early stage - recombinant MVA may do this [41] and it has been successfully used for in ovo vaccination [16] - and the boost should be given with a highly immunogenic protein - as pVP2 - around 14 days after prime to achieve high levels of protection by the time when chicks become more susceptible to the infection. In spite of this, it remains unclear whether the humoral or the cellular branch of the immune response is the most important against IBDV, but this study is to be taken as a starting point to explore the mechanisms through which recombinant MVA can enhance anti-IBDV protective efficacy in the chicken.

\section{Conflict of interest}

The authors confirm that they have no conflict of interests.

\section{Acknowledgements}

Authors want to acknowledge Mr. Silvio Díaz for taking care of the animals, Dr. Lomonossoff (John Innes Centre, UK) for giving the pEAQ vectors and Vet. Silvina Pinto for the assistance with histopathological analyses. This work was supported by grants PNBIO 1131032 from INTA and PICT 2011-1023 from ANPCyT, Argentina.

\section{Appendix A. Supplementary material}

Supplementary data associated with this article can be found, in the online version, at http://dx.doi.org/10.1016/j.vaccine.2016.11. 029.

\section{References}

[1] Saif YM. Immunosuppression induced by infectious bursal disease virus. Vet Immunol Immunopathol 1991;30:45-50. http://dx.doi.org/10.1016/01652427(91)90007-Y.

[2] Müller H, Scholtissek C, Becht $\mathrm{H}$. The genome of infectious bursal disease virus consists of two segments of double-stranded RNA. J Virol 1979;31:584-9.

[3] Yamaguchi T, Iwata K, Kobayashi M, Ogawa M, Fukushi H, Hirai K. Epitope mapping of capsid proteins VP2 and VP3 of IBDV. Arch Virol 1996:1:1493-507.

[4] Sharma JM, Kim IJ, Rautenschlein S, Yeh HY. Infectious bursal disease virus of chickens: pathogenesis and immunosuppression. Dev Comp Immunol 2000;24:223-35. http://dx.doi.org/10.1016/S0145-305X(99)00074-9.

[5] Jackwood DJ, Sommer-Wagner S. Genetic characteristics of infectious bursal disease viruses from four continents. Virology 2007;365:369-75. http://dx.doi. org/10.1016/i.virol.2007.03.046.

[6] Müller H, Mundt E, Eterradossi N, Islam MR. Current status of vaccines against infectious bursal disease. Avian Pathol 2012;41:133-9. http://dx.doi.org/ 10.1080/03079457.2012.661403.

[7] Alkie TN, Rautenschlein S. Infectious bursal disease virus in poultry: current status and future prospects. Vet Med Res Reports 2016:7:9-18.

[8] Gómez E, Lucero MS, Chimeno Zoth S, Carballeda JM, Gravisaco MJ, Berinstein A. Transient expression of VP2 in Nicotiana benthamiana and its use as a plantbased vaccine against Infectious Bursal Disease Virus. Vaccine 2013;31:2623-7. http://dx.doi.org/10.1016/i.vaccine.2013.03.064.

[9] Zanetti FA, Zajac MPDM, Taboga OA, Calamante G. Evaluation of modified vaccinia virus Ankara expressing VP2 protein of infectious bursal disease virus as an immunogen in chickens. vol. 13; 2012. http://dx.doi.org/10.4142/ivs. 2012.13.2.199.

[10] Zanetti FA, Grand MDC, Mitarotonda RC, Taboga OA, Calamante G. Canarypox virus expressing infectious bursal disease VP2 protein as immunogen for chickens. Brazilian J Microbiol 2014;45:231-4. http://dx.doi.org/10.1590/ S1517-83822014000100032.

[11] Zanetti FA, Cardona R, Federico CR, Chimeno-Zoth S, Calamante G. Recombinant canarypox virus expressing the VP2 protein of infectious bursal disease virus induces protection in vaccinated SPF chickens. Virol Sin 2016:1-5. http://dx.doi.org/10.1007/s12250-015-3680-6.

[12] Lu S. Heterologous prime-boost vaccination. Curr Opin Immunol 2009;21:346-51. http://dx.doi.org/10.1016/j.coi.2009.05.016.

[13] Cottingham MG, Carroll MW. Recombinant MVA vaccines: dispelling the myths. Vaccine 2013;31:4247-51. http://dx.doi.org/10.1016/ i.vaccine.2013.03.021.

[14] Schulze K, Staib C, Schätzl HM, Ebensen T, Erfle V, Guzman Ca. A prime-boost vaccination protocol optimizes immune responses against the nucleocapsid protein of the SARS coronavirus. Vaccine 2008;26:6678-84. http://dx.doi.org/ 10.1016/i.vaccine.2008.09.00.

[15] Jaramillo Ortiz JM, Del Médico Zajac MP, Zanetti FA, Molinari MP, Gravisaco MJ, Calamante G, et al. Vaccine strategies against Babesia bovis based on prime-boost immunizations in mice with modified vaccinia Ankara vector and recombinant proteins. Vaccine 2014;32:4625-32. http://dx.doi.org/10.1016/ j.vaccine.2014.06.075.

[16] Boyd AC, Ruiz-Hernandez R, Peroval MY, Carson C, Balkissoon D, Staines K, et al. Towards a universal vaccine for avian influenza: protective efficacy of modified Vaccinia virus Ankara and Adenovirus vaccines expressing conserved influenza antigens in chickens challenged with low pathogenic avian influenza virus. $\quad$ Vaccine 2013;31:670-5. http://dx.doi.org/10.1016 i.vaccine.2012.11.047.

[17] Rerks-Ngarm S, Pitisuttithum P, Nitayaphan S, Kaewkungwal J, Chiu J, Paris R, et al. Vaccination with ALVAC and AIDSVAX to prevent HIV-1 infection in Thailand. N Engl J Med 2009;361:1209-23. http://dx.doi.org/10.1056/ NEJMoa1203165.

[18] Peyret H, Lomonossoff GP. The pEAQ vector series: the easy and quick way to produce recombinant proteins in plants. Plant Mol Biol 2013;83:51-8. http:// dx.doi.org/10.1007/s11103-013-0036-1.

[19] Carballeda JM, Zoth SC, Gómez E, Gravisaco MJ, Berinstein A. Activation of the immune response against Infectious Bursal Disease Virus after intramuscular inoculation of an intermediate strain. Immunobiology 2011;216:1028-33. http://dx.doi.org/10.1016/i.imbio.2011.03.003.

[20] Reed LJ, Muench H. A simple method of estimating fifty percent endpoints. Am J Epidemiol 1938;27:493-7.

[21] Kim IJ, You SK, Kim H, Yeh HY, Sharma JM. Characteristics of bursal T lymphocytes induced by infectious bursal disease virus. J Virol 2000;74:8884-92. http://dx.doi.org/10.1128/JVI.74.19.8884-8892.2000.

[22] Singh J, Banga HS, Brar RS, Singh ND, Sodhi S, Leishangthem GD. Histopathological and immunohistochemical diagnosis of infectious bursal disease in poultry birds. Vet World 2015;8:1331-9. http://dx.doi.org/ 10.14202/vetworld.2015.1331-1339.

[23] Mahgoub HA. An overview of infectious bursal disease. Arch Virol 2012;157:2047-57. http://dx.doi.org/10.1007/s00705-012-1377-9.

[24] Kardani K, Bolhassani A, Shahbazi S. Prime-boost vaccine strategy against viral infections: mechanisms and benefits. Vaccine 2016;34:413-23. http://dx.doi. org/10.1016/i.vaccine.2015.11.062.

[25] Musich T, Robert-Guroff M. New developments in an old strategy: heterologous vector primes and envelope protein boosts in HIV vaccine design. Expert Rev Vaccines 2016:1-13. http://dx.doi.org/10.1586/ 14760584.2016.1158108.

[26] Ramshaw IA, Ramsay AJ. The prime-boost strategy: exciting prospects for improved vaccination. Immunol Today 2000;21:163-5. http://dx.doi.org/ 10.1016/S0167-5699(00)01612-1.

[27] Woodland DL. Jump-starting the immune system: prime-boosting comes of age. Trends Immunol 2004;25:98-104. http://dx.doi.org/10.1016/j. it.2003.11.009.

[28] Yan F, Zhao Y, Hu Y, Qiu J, Lei W, Ji W, et al. Protection of chickens against infectious bronchitis virus with a multivalent DNA vaccine and boosting with an inactivated vaccine. J Vet Sci 2013;14:53-60. http://dx.doi.org/10.4142/ jvs.2013.14.1.53.

[29] Hsieh MK, Wu CC, Lin TL. Priming with DNA vaccine and boosting with killed vaccine conferring protection of chickens against infectious bursal disease. Vaccine 2007;25:5417-27. http://dx.doi.org/10.1016/j.vaccine.2007.04.087.

[30] Firouzamandi M, Moeini H, Hosseini D, Hair Bejo M, Omar AR, Mehrbod P, et al. Improved immunogenicity of Newcastle disease virus fusion protein genes. J Vet Sci 2016:17:21-6.

[31] Ferreira HL, Rauw F, Pirlot JF, Reynard F, van den Berg T, Bublot M, et al. Comparison of single 1-day-old chick vaccination using a Newcastle disease virus vector with a prime/boost vaccination scheme against a highly pathogenic avian influenza H5N1 challenge. Avian Pathol 2014;43:68-77. http://dx.doi.org/10.1080/03079457.2013.873111.

[32] Gao H, Li K, Gao L, Qi X, Gao Y, Qin L, et al. DNA prime-protein boost vaccination enhances protective immunity against infectious bursal disease virus in chickens. Vet Microbiol 2013;164:9-17. http://dx.doi.org/10.1016/i. vetmic.2013.01.027.

[33] Steensels M, Bublot M, Van Borm S, De Vriese J, Lambrecht B, Richard-Mazet A, et al. Prime-boost vaccination with a fowlpox vector and an inactivated avian 
influenza vaccine is highly immunogenic in Pekin ducks challenged with Asian H5N1 HPAI. Vaccine 2009;27:646-54. http://dx.doi.org/10.1016/ i.vaccine. 2008.11.044.

[34] Vaine M, Wang S, Hackett A, Arthos J, Lu S. Antibody responses elicited through homologous or heterologous prime-boost DNA and protein vaccinations differ in functional activity and avidity. Vaccine 2010;28:2999-3007. http://dx.doi.org/10.1016/i.vaccine.2010.02.006.

[35] Ingrao F, Rauw F, Lambrecht B, Van den Berg T. Infectious bursal disease: a complex host-pathogen interaction. Dev Comp Immunol 2013;41:429-38. http://dx.doi.org/10.1016/i.dci.2013.03.017.

[36] Yeh HY, Rautenschlein S, Sharma JM. Protective immunity against infectious bursal disease virus in chickens in the absence of virus-specific antibodies. Vet Immunol Immunopathol 2002;89:149-58. http://dx.doi.org/10.1016/S01652427(02)00206-4.

[37] Arnold M, Durairaj V, Mundt E, Schulze K, Breunig KD, Behrens SE. Protective vaccination against infectious bursal disease virus with whole recombinant kluyveromyces lactis yeast expressing the viral VP2 subunit. PLOS ONE 2012;7:1-11. http://dx.doi.org/10.1371/journal.pone.0042870.
[38] Robinson HL, Montefiori DC, Johnson RP, Manson KH, Kalish ML, Lifson JD, et al. Neutralizing antibody-independent containment of immunodeficiency virus challenges by DNA priming and recombinant pox virus booster immunizations. Nat Med 1999;5:526-34. http://dx.doi.org/10.1038/8406.

[39] Matteucci D, Pistello M, Mazzetti P, Giannecchini S, Del Mauro D, Zaccaro L et al. Vaccination protects against in vivo-grown feline immunodeficiency virus even in the absence of detectable neutralizing antibodies. J Virol 1996;70:617-22.

[40] Rautenschlein S, Yeh HY, Njenga MK, Sharma JM. Role of intrabursal T cells in infectious bursal disease virus (IBDV) infection: T cells promote viral clearance but delay follicular recovery. Arch Virol 2002;147:285-304. http://dx.doi.org 10.1007/s705-002-8320-2.

[41] Stittelaar KJ, Wyatt LS, de Swart RL, Vos HW, Groen J, van Amerongen G, et al. Protective immunity in macaques vaccinated with a modified vaccinia virus ankara-based measles virus vaccine in the presence of passively acquired antibodies. J Virol 2000;74:4236-43. http://dx.doi.org/10.1128/IVI.74.9.4236 4243.2000. 